\title{
PROPUESTA DE INTERVENCIÓN URBANO-ARQUITECTÓNICA DE "LA BAJADA VIEJA", POSADAS, MISIONES
}

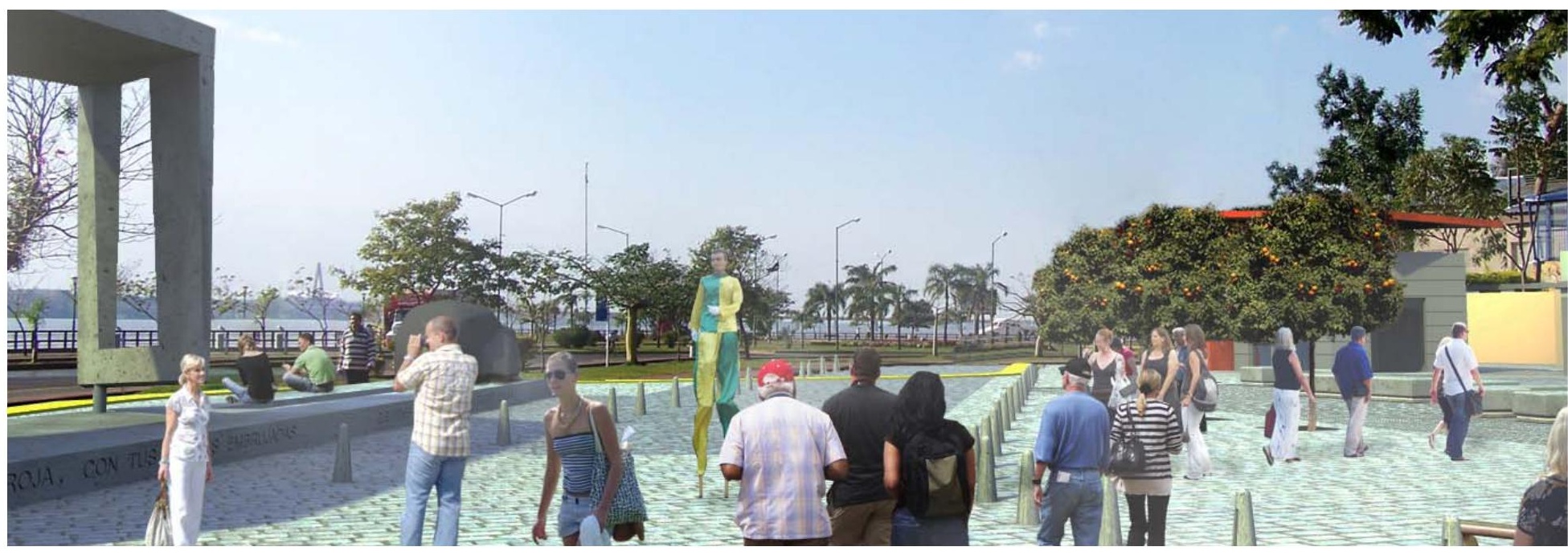




\section{RESUMEN}

El presente artículo tiene por objetivo exponer las decisiones de diseño efectuadas para la propuesta del concurso realizado en la ciudad de Posadas (Misiones, Argentina), ganadora del 1.er Premio Diseño y Planificación del Paisaje en la categoría menores de cuarenta años de la Bienal Nacional de Diseño, organizada por la Facultad de Arquitectura, Diseño y Urbanismo de la Universidad Nacional de Buenos Aires y la Red Argentina de las Carreras de Diseño en las Universidades Nacionales. Asimismo el trabajo ha sido galardonado con el $2 .^{\circ}$ Premio Concurso Internacional de Ideas Costa Central Uno Posadas, tema Bajada Vieja.

\section{ABSTRACT}

The present article has for aim to expose the design decisions of the proposed winner of the first prize in the contest "Design and Planning of the Landscape", (in the category under forty-yearold) of the National Biennial Design, realized in the city of Posadas (Misiones, Argentina) and organized by the Faculty of Architecture, Design and Urbanism of the National University of Buenos Aires and the Argentina Network of the Careers of Design in the National Universities. This work has also been awarded the 2nd International Ideas Competition Award "Central Coast One Posadas", topic Bajada Vieja.

\section{CLAUDIA PILAR}

Arquitecta, magíster en Gestión Ambiental, especialista en Docencia Universitaria. Profesora titular de Construcción de Edificios I (FI-UNNE), JTP Construcciones II (FAU-UNNE). Coordinadora de la Carrera de Posgrado Especialización en Evaluación Ambiental (FAU-UNNE).

\section{MARIA JOSE ROIBÓN}

Arquitecta, magíster en Gestión del Ambiente, el Paisaje y el Patrimonio. Especialista en Docencia Universitaria. Especialista en Cooperación Internacional AL-UE. Docente de la Facultad de Arquitectura y Urbanismo de la UNNE en las asignaturas Morfología II y Arquitectura Paisajística. Subsecretaria de Planificación Estratégica de la Municipalidad de Resistencia, Chaco. 


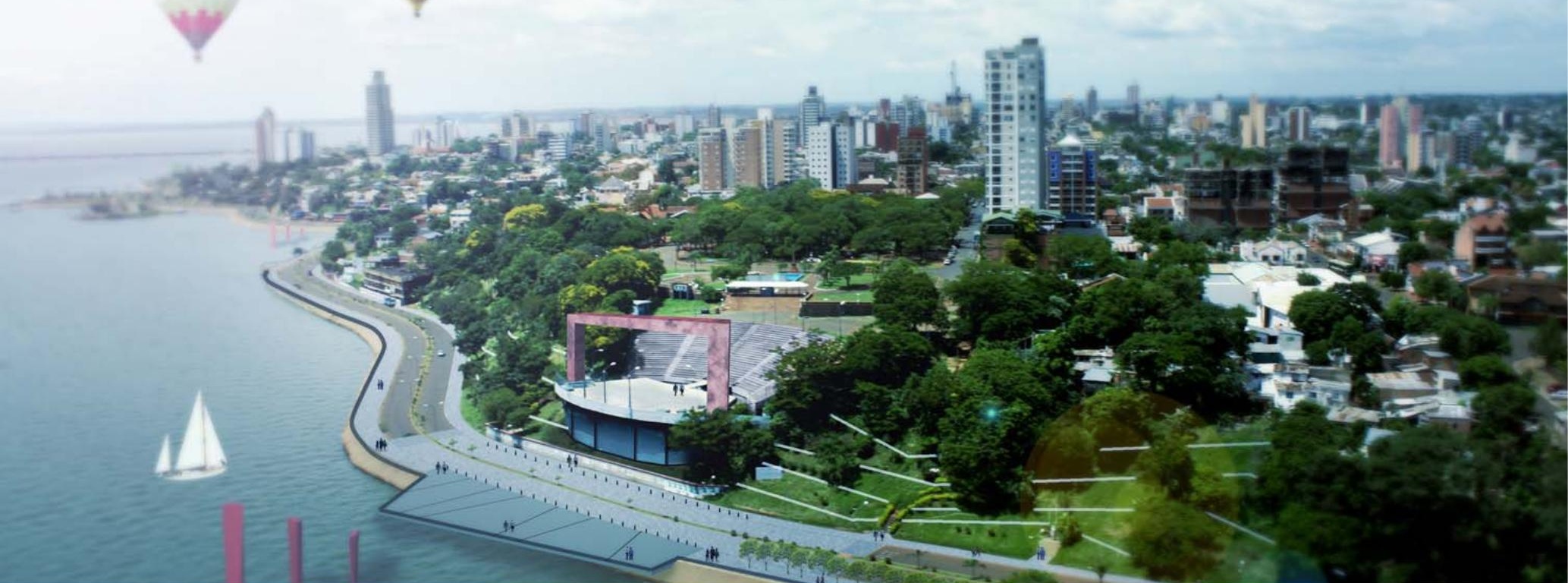

[Figura 1. Vista general diurna y noctura de la costa de Posadas con la intervención a nivel urbano, derramando la propuesta de diseño de la Bajada Vieja a su entorno]

\section{APROXIMACIÓN A LA ESCALA TERRITORIAL. EL SITIO}

"... Qué tienes, mi tierra roja, con tus noches embrujadas..." Posadeña Linda. Ramón Ayala

La propuesta parte de la situación territorial en la que se inserta la ciudad de Posadas, capital de la provincia de Misiones, íntimamente relacionada con la ciudad de Encarnación, segunda ciudad de la hermana República de Paraguay.

Ambas ciudades conforman un conglomerado de medio millón de habitantes, con situaciones históricas y geográficas diferentes, pero con las mismas problemáticas sociales y económicas, y una relación funcional intensa de intercambio de personas, bienes y servicios.

Por este motivo, es importante pensar un diseño urbano y arquitectónico para la ciudad, que conserve su memoria y valores históricos, proponiendo formas y tecnologías apropiadas sobre uso y la degradación propia de los espacios públicos; planteos funcionales flexibles acordes con los usos actuales y posibilidades futuras, alternativas sustentables y con compromiso social.

Se realizó una propuesta urbano-ambiental, a partir de tres ideas fuerza:

1. Ciudad Sustentable. La conformación de un sistema de espacios verdes significativos, vinculados entre sí mediante corredores verdes urbanos con su respectiva propuesta paisajística-ambiental; incorporando actividades con una nueva dinámica eco-urbana.

2. Memoria urbana colectiva. Conformación de un circuito patrimonial, donde se incluye la vinculación de los edificios de valor histórico-patrimonial existentes y una reelaboración de la memoria de la "Trinchera", a partir de una propuesta de intervención en el espacio público que reconstituye su trayecto.

3. Ciudad inteligente. Incorporación del concepto de "ciudad inteligente" o smart cities, donde se introduzca al ciudadano en un sistema de tecnología de la in-

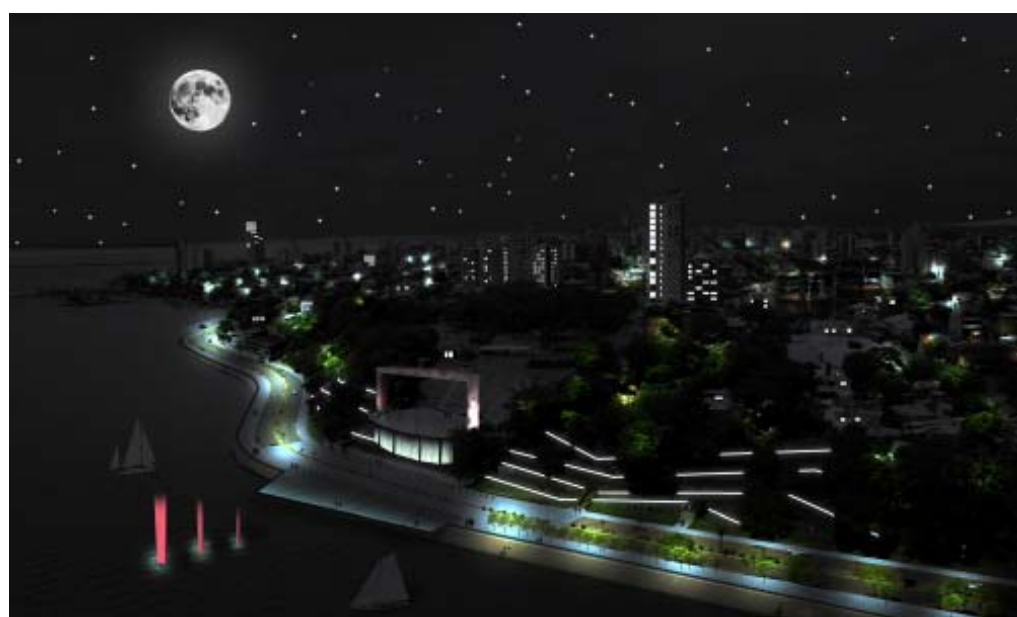

formación para que sepa con qué servicios puede contar y cómo puede sacar el máximo provecho de ello, desde el sector de intervención, para ser replicado luego en toda la ciudad, comenzando por unificar el lenguaje del equipamiento y la señalética urbana. (Figura 1. Vista general de la costa de Posadas con la intervención a nivel urbano, derramando la propuesta de diseño de la Bajada Vieja a su entorno. Fuente: elaboración propia)

Así, la propuesta urbana se apoya en pautas que contemplan la identidad del lugar y la cohesión entre lo cultural y lo natural, lo antrópico y lo vegetal, incorporando el paisaje natural del entorno próximo y propuestas contemporáneas de usos y materialización.

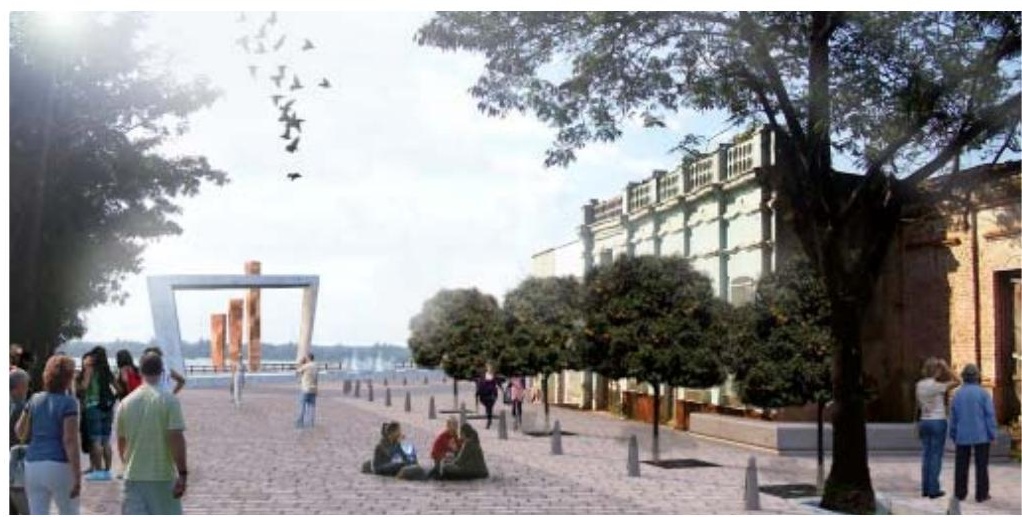

[Figura 2. Remate de la Bajada Vieja en su llegada al río Paraná. Se propone una "ventana mirador" que propicie la contemplación del binomio naturalezacultura, representado por el río-escultura] 


\section{PROCESO DE DISEÑO}

Para la propuesta se tuvieron en cuenta las siguientes pautas generales:

- Resaltar aspectos relativos a la memoria colectiva y la Bajada Vieja como principal referente de la ciudad.

- Apropiarse de los bordes del perímetro del área de intervención directa, de manera de establecer un contacto franco con el entorno.

- Conservar la vegetación y sectores existentes de alto valor histórico y social, potenciándolos desde el punto de vista arquitectónico, ambiental y paisajístico.

- Generar una propuesta conceptualmente superadora a la actual, con criterios de sustentabilidad ambiental y respeto por la identidad.

\section{LÓGICA SITUACIONAL}

"... Y me fui por la Bajada Vieja, donde un día conocí el amor, y crucé por sus calles de tierra, con el alma llena de ilusión, pero solo me esperaba el río, acariciándome el corazón..." Posadeña Linda. Ramón Ayala

El área de la Bajada Vieja representa el sector más antiguo de la ciudad de Posadas, con una fuerte correspondencia con la funcionalidad del puerto, la topografía del sitio (con una pendiente apreciable) y su relación con la antigua Trinchera San José.

RAMÓN GUTIÉRREZ, en El Patrimonio Arquitectónico de los argentinos, define a la Bajada Vieja como un sector urbano de Posadas que ha sabido crear un ritmo propio de vida, y que también tuvo sus características arquitectónicas propias.

Su forma no responde a una propuesta de diseño planifica$\mathrm{da}$, sino que se ha ido construyendo con el paso del tiempo, por la sumatoria de intervenciones individuales, en general conectadas a la función comercial y mercantil del área.

Según las palabras de LOUIS KHAN el genius loci denota lo que una cosa es o lo "que quiere ser". La propuesta intenta interpretar esta vocación del sitio como área destinada a la convivencia armónica de funciones distintas, pero complementarias, como por ejemplo la residencial (preponderante hasta el momento), la actividad turística, artística y comercial (de baja escala y con bajo impacto ambiental).
Esta idea revaloriza el concepto de lugar como estructurador del conjunto en relación con el entorno urbano remoto, considerando el sistema de espacios públicos en el que se inserta, teniendo en cuenta los usos cotidianos y las actividades que se desarrollan en su perímetro, de manera que La Bajada penetre en el entorno y, a su vez, el entorno penetre en La Bajada, en diálogo armónico entre sector y conjunto.

Por ello se pretende "ligar" La Bajada al espacio urbano contiguo, a través del equipamiento urbano propuesto (iluminación, bancos, basureros, solados), donde a partir de la lógica de relaciones se materialicen dos situaciones:

- Relación Bajada-Ciudad: con vinculaciones que dialogan con la geometría del tejido urbano, donde el solado de la bajada se esparce hacia el entorno y líneas rectas "cosen" ambos lados de la calle.

- La Bajada como espacio de contemplación de la naturaleza circundante: para ello se plantea una serie de "ventanas urbanas", que enmarcan el escenario natural capturando y mediatizando la relación entre paisaje natural y construido en una sinergia escenográfica.

El diseño de La Bajada se derrama en su entorno inmediato. Se realiza una propuesta integradora del entorno inmediato a partir del mobiliario urbano, que son los elementos que el peatón encuentra a su paso, para facilitar sus necesidades y mejorar las condiciones de uso del espacio público.

En cuanto a la vegetación, se propone una interrelación entre La Bajada y el entorno, a partir de la continuidad de algunas especies existentes, o propuestas en el sector hacia el entorno, de manera de generar corredores verdes que mejoren el paisaje urbano y las condiciones ambientales, al mismo tiempo que fortalezcan la vinculación entre el sitio, su entorno y el sistema de espacios verdes públicos.

Como consecuencia de estas pautas, la propuesta de La Bajada se plantea como una circulación de baja velocidad, una calle peato-vehicular en la que los límites entre vereda y calle se desdibujan (preservando la seguridad de circulación de los peatones). El tradicional "cordón" que marca el límite entre el espacio destinado a los peatones y el de los automóviles se pierde, y es reemplazado funcionalmente con una rejilla, que permite el desagüe del agua de origen pluvial, y "separadores" de hormigón que demarcan la línea entre tránsito peatonal y vehicular.

También se propone el concepto de circulación peato-vehicular para la calle Lezcano, desde Bajada Vieja hasta avenida 


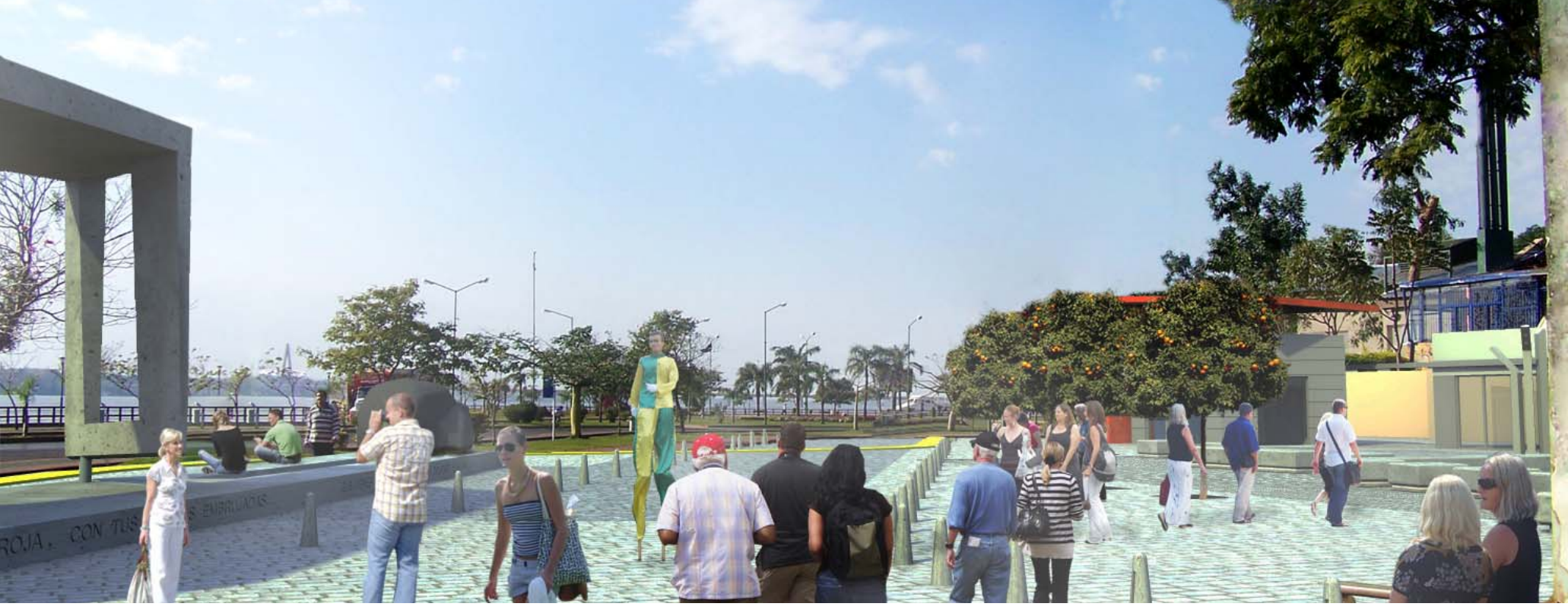

[Figura 5. Propuesta espacial. Mediante la propuesta de calle peato-vehicular]

Roque Pérez, integrada totalmente al diseño, de expansión natural del Rincón del Mensú. La calle Lezcano, desde Bajada Vieja, hasta Sánchez Ratti, se interviene con los mismos elementos de diseño, proponiendo asimismo un sector denominado "Patio urbano de la Expresión", utilizando el desnivel natural y haciendo de la "espalda" del Rincón del Mensú un lugar propicio para el desarrollo de expresiones espontáneas de carácter artístico, folclórico, o simplemente para el encuentro y el disfrute bajo la sombrilla vegetal del sector.

\section{LÓGICA FUNCIONAL}

Se estructura el conjunto a partir del lugar más significativo de la Bajada Vieja. Se conforma un sistema de lugares peatonales con los demás itinerarios propuestos en el recorrido, que se vinculan entre sí y con el entorno. La idea es crear un itinerario turístico-recreativo-cultural atractivo y singular, en relación con la ciudad y región en la que se inserta, haciendo visibles y potenciando sitios de interés, de acuerdo con su valor situacional, histórico, cultural o ambiental.

Figura 5. Propuesta espacial. Mediante la propuesta de calle peato-vehicular, se genera un espacio de convivencia de diferentes actividades de carácter cultural, turístico y recreativo. (Imagen 4)

Así, se definen los siguientes lugares (entre otros):

-Rincóndel Mensú. Eselespacio principal del Paseo Bajada Vieja.

- Patio Urbano de la Expresión. Explanada que sirva para expresiones artísticas múltiples y espontáneas (como por

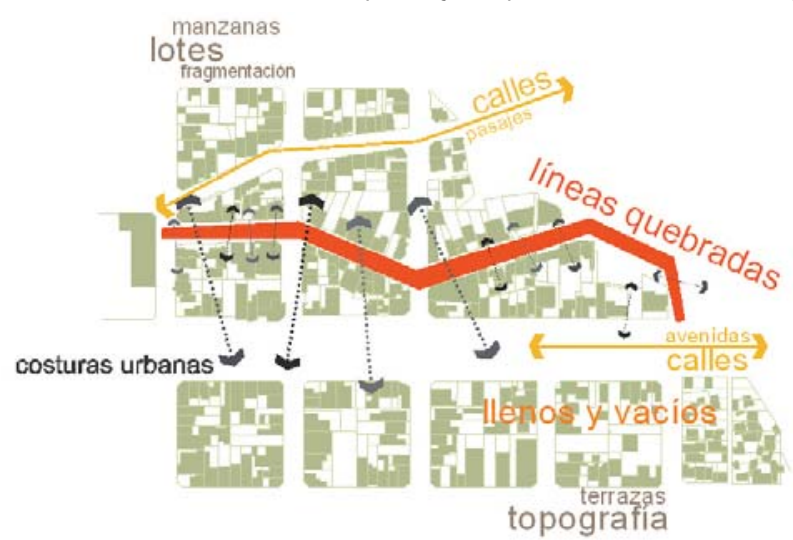

[Figura 4. Planta esquemática de la Bajada Vieja, su entorno y los lotes circundantes que determinaron la lógica formal-simbólica de la propuesta. Elaboración Propia.] ejemplo musicales, teatro, expresión corporal, etc.), y donde se revalorice la esencia artística del ser misionero. - Mirador Piedra Fundamental. En el remate de la Bajada Vieja se propone una "ventana" al río que enmarca el paisaje e integra formal y espacialmente a la Piedra Fundamental (referencia histórica de la ciudad, para conservar y revalorizar). - Ventana del cerro Pelón. Otra ventana al río como remate de la calle bajada vieja en el cerro Pelón, que se complementa con esculturas relacionadas con el tema desarrollado.

- Senda de los Azahares. Se proponen azahares, ubicados en cubrealcorques, que recrean un paisaje urbano diferente pero referente.

\section{LÓGICA SIMBÓLICA FORMAL}

Se incorpora como elemento significativo en la propuesta la línea quebrada de ángulos irregulares, que representa la fragmentación urbana, su diversidad, el paso del tiempo, la construcción colectiva, la negociación entre lo público y lo privado. Esta línea quebrada de ángulos irregulares se materializa en texturas de los solados, bordes y equipamiento; trabajando la topografía con movimientos de suelos con ondulaciones en ángulos vivos resaltados por líneas de iluminación de LED; con el agua presente en las rajas del suelo: los elementos arquitectónicos propuestos (ventanas urbanas $y$ edificios para el turismo y la cultura).

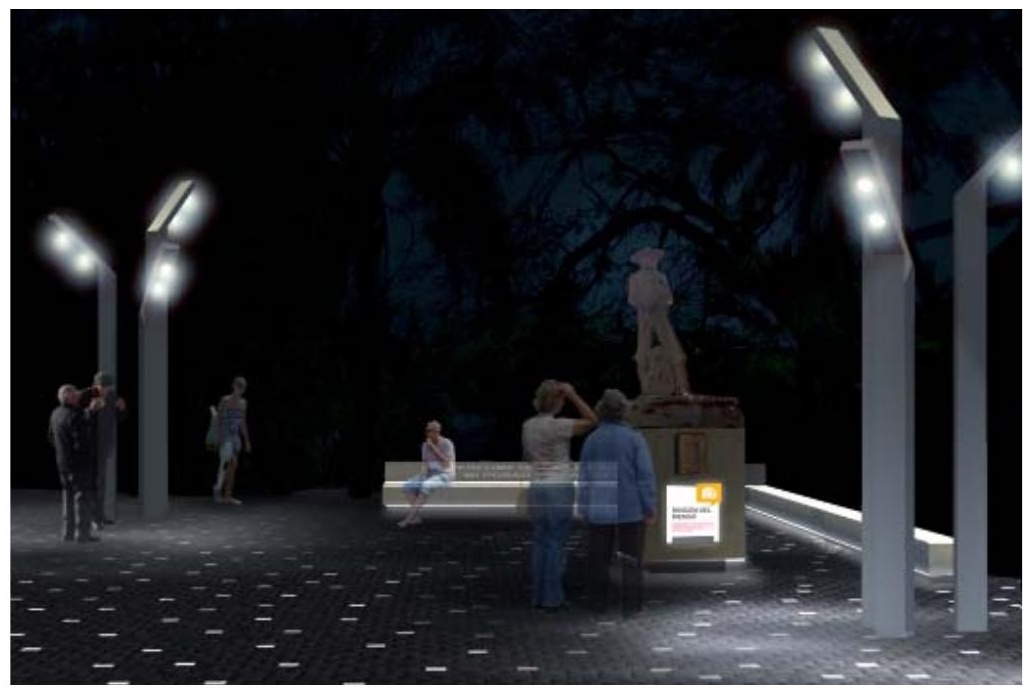

[Figura 6. Propuesta de intervención del "Rincón del Mensú" fuente: elaboración propia] 


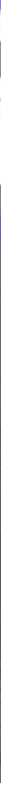

[Figura 6. Propuesta de intervención del "Rincón del Mensú" fuente: elaboración propia]

La geometría de la Bajada Vieja, la de la calle Coronel Álvarez, el trazado de la Trinchera San José y el borde costero representan las formas que han inspirado la lógica geométrica de la propuesta. Estas características del sitio, cuya disposición no responde a la trama ortogonal del resto de la ciudad, se presentan como una fuerte condicionante de diseño.

La lógica geométrica propuesta (que refuerza la que naturalmente tiene el sitio) se expande desde La Bajada hacia el entorno. La propuesta tiende a reforzar esa idea de ruptura de trama incorporando líneas quebradas.

El borde costero se integra a esta lógica geométrica, que va cociendo la geometría propuesta con la trama existente.

\section{PROPUESTA ARQUITECTÓNICA}

En la Bajada Vieja existen edificios declarados de interés histórico y otros cuyo potencial es rescatado para su revalorización. Asimismo existen otros edificios, de variadas características, cuyo tratamiento de forma consensuada y participativa con los vecinos permitirá reforzar la identidad del sitio, logrando una variedad de respuestas, pero con criterios de armonía, para conformar un nuevo telón urbano.

\section{Edificios declarados Patrimonio Cultural por Ordenanza N. 46/097.}

Los edificios declarados Patrimonio Cultural son suficientemente preservados y revalorizados. Se propone un tratamiento a través de los colores, la iluminación, la señalización y las leyendas, que permita revalorizar los edificios en su contexto.

Los edificios declarados Patrimonio Cultural que se encuentran en La Bajada son los siguientes:

\section{Escuela Mundo Niño}

Se propone conservar los ladrillos a la vista y pintar el zócalo de color teja, para unificarlo. En la vereda se dispondrán luces de piso de forma aleatoria. Su condición de edificio de interés patrimonial se destacará mediante el sistema de señalética urbana, con un "Identificador + Info", donde se haga referencia al nombre del edificio, constructor/arquitecto y año de edificación.

\section{Casona Chemes}

Se propone conservar el color, característico de este tipo de edificaciones, en un tono "Piedra París". En la vereda se dispondrán luces de piso de forma aleatoria. Su condición de edificio de interés patrimonial se destacará mediante el sistema de señalética urbana, con un "Identificador + Info", donde se haga referencia al nombre del edificio, constructor/ arquitecto y año de edificación.

\section{Esquina bar El Mensú}

Se propone conservar los ladrillos a la vista de la planta alta y pintar la planta baja de color teja, para unificarlo. En la vereda se dispondrán luces de piso de forma aleatoria. Su condición de edificio de interés patrimonial se des-
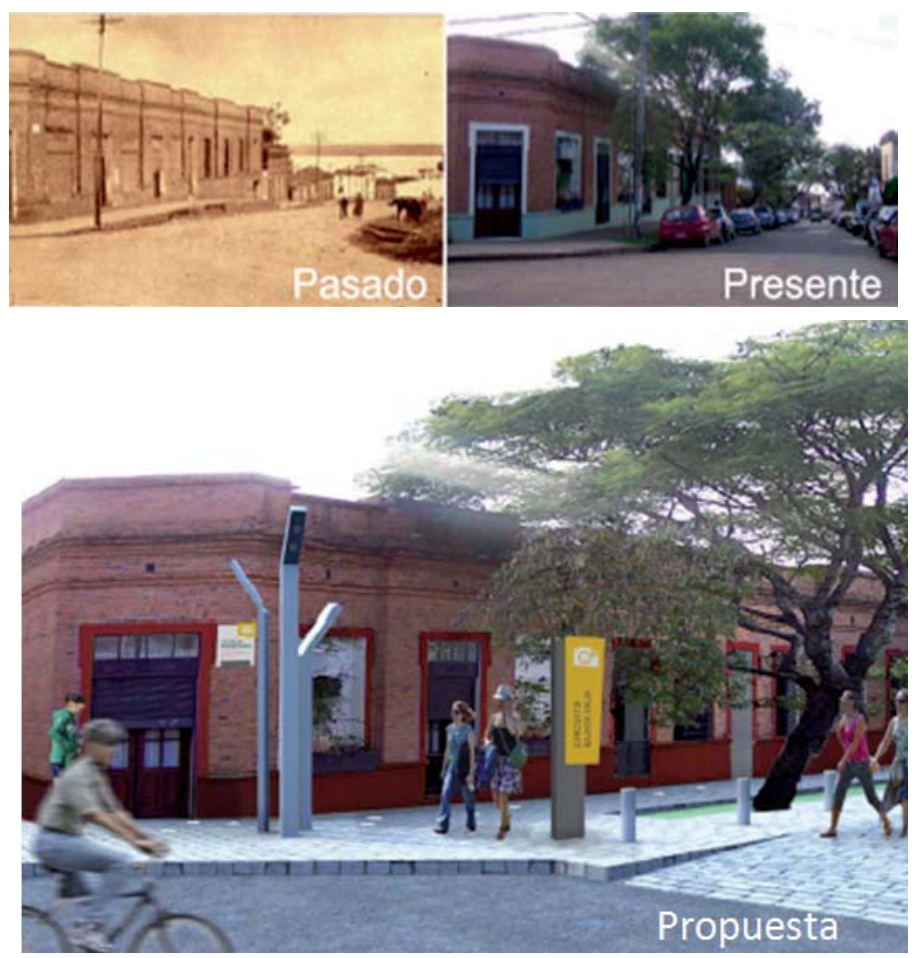

[Figura 7. Escuela Mundo Niño. Imágenes que sintetizan el proceso de análisis de los edificios declarados de interés patrimonial y las propuestas de intervención. Se observa también el equipamiento urbano y la señalética diseñada al efecto. Fuente: elaboración propia]

tacará mediante el sistema de señalética urbana, con un "Identificador + Info", donde se haga referencia al nombre del edificio, constructor/arquitecto y año de edificación. 


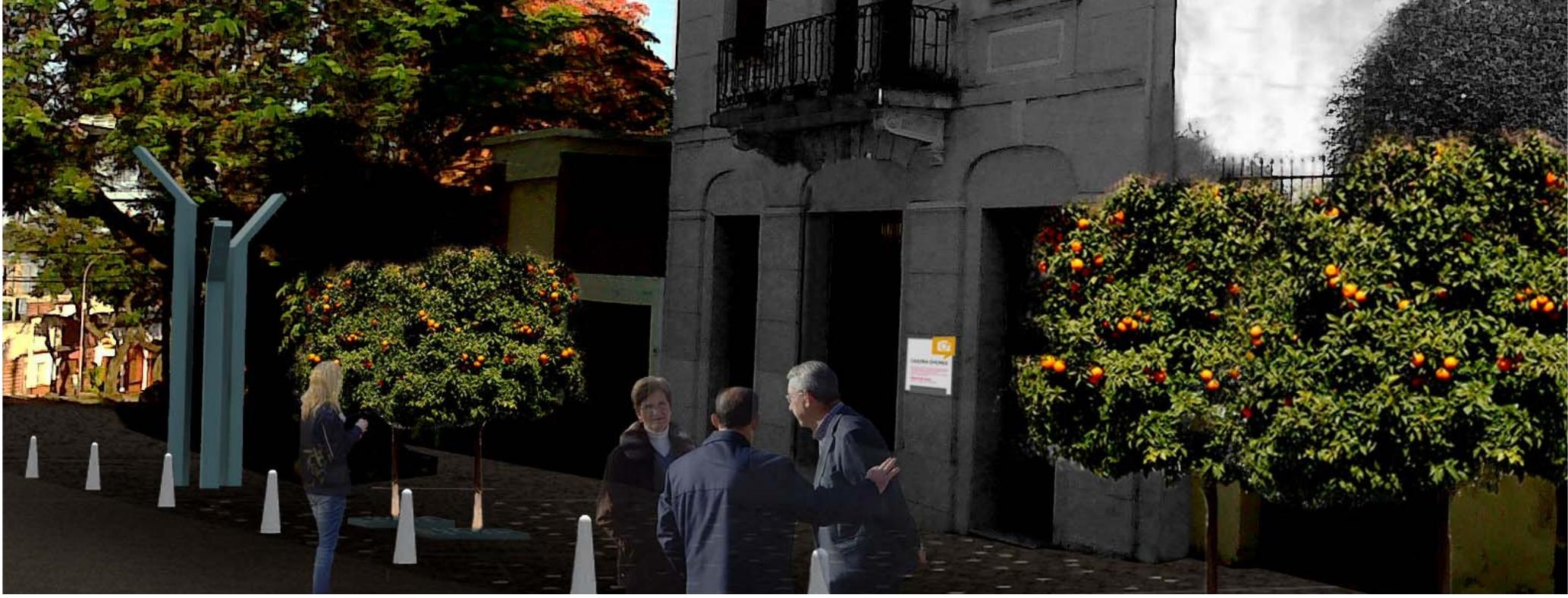

[Figura 8. Propuesta de intervención en Casona Chemes. Imagen diurna (arriba) y noctura (abajo). Fuente: elaboración propia]

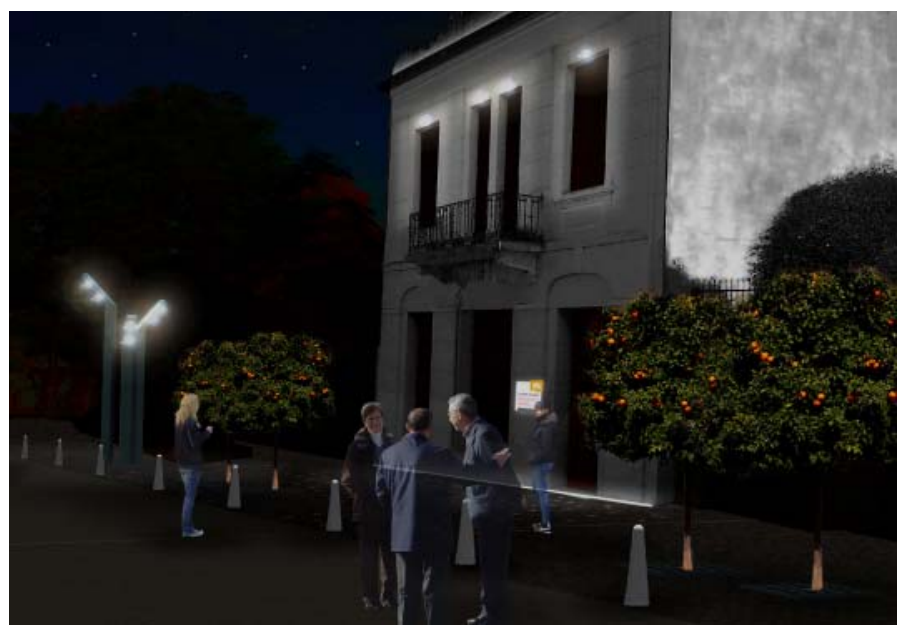

Tienda de Antonio Julián (actual ICE)

Se propone conservar los ladrillos a la vista de la fachada, así como el zócalo de las escalinatas exteriores de piedra basáltica, característico de la zona.

Con respecto a las ampliaciones realizadas en la planta alta, que modifican sustancialmente el diseño original, se propone su unificación mediante el uso del color terracota y una barrera vegetal para mitigar el impacto visual de dichas intervenciones. En la vereda se dispondrán luces de piso de forma aleatoria. Su condición de edificio de interés patrimonial se destacará mediante el sistema de señalética urbana, con un "Identificador + Info", donde se haga referencia al nombre del edificio, constructor/arquitecto y año de edificación.

\section{Propuesta de edificios para revalorizar}

Se verifica una serie de edificios de valorables condiciones espaciales y significativas que no se encuentran dentro de las consideradas de valor patrimonial por la normativa vigente, pero que la presente propuesta propone incorporar al recorrido y otorgarle características que condigan con la propuesta general urbana y particular del sector. El mecanismo para su incorporación se contempla en el apartado correspondiente a la propuesta de herramientas de gestión.

Sector de propiedades subutilizadas o en estado de abandono Se propone conservar los ladrillos a la vista. En la vereda se dispondrán luces de piso de forma aleatoria.

\section{Otros edificios de La Bajada.}

Si bien en La Bajada existen muchos edificios, algunos de los cuales no revisten mayor valor patrimonial, se propone como criterio de intervención, mediante un proceso de validación consensuado por los vecinos, la intervención de estos, tendiente a lograr una mayor unidad de criterios.

En alguno de ellos se propone que se vuelva al ritmo original de aventanamiento, desvirtuado por intervenciones sin criterios; en otros (caso de la despensa), se propone eliminar la marquesina, unificar colores y limitar la cartelería comercial. Los colores propuestos son los de la gama de los tonos terracota, característicos de Misiones y Posadas, para hacer honor a la arquitectura ladrillera de carácter utilitario que caracterizó el sector.

Propuesta paisajística "... El perfume que en la noche enciende mi Posadas Ilena de azahar..." Posadeña Linda; Ramón Ayala

Las cualidades inconmensurables de la vegetación, como lo son la regulación del oxígeno, la modificación del ambiente urbano (rehidratando la atmósfera, refrescando el aire, interceptando la radiación solar, mitigando la contaminación sonora y la contaminación química), se suman a la satisfacción de las necesidades psicológicas, sociales y culturales de las personas.

La vegetación es el elemento fundamental que nos brinda la naturaleza y que está dotado de un cúmulo de características particulares, como los olores, los colores, las magnitudes.

Por este motivo es que se conservan las especies existentes, ya que se las considera de gran valor paisajístico y ambiental por sus características morfológicas, de colores y texturas, su porte y significado como parte de la memoria colectiva del lugar y sus habitantes.

La propuesta se realiza contemplando la necesidad de intensificar la vegetación en algunos sectores, resaltar especies significativas y caracterizar sendas o lugares, de manera de dar mayor "legibilidad" a cada rincón del espacio público propuesto y de convertir a la bajada en una especie de parque lineal con un volumen importante de masa verde.

Para la calle Flemig se propone la "senda de los azahares", haciendo alusión a la flor de naranjo (Citrus aurantium) programando la plantación de especies de manera continua sobre mano derecha entre Reguera y Lezcano, y completando 


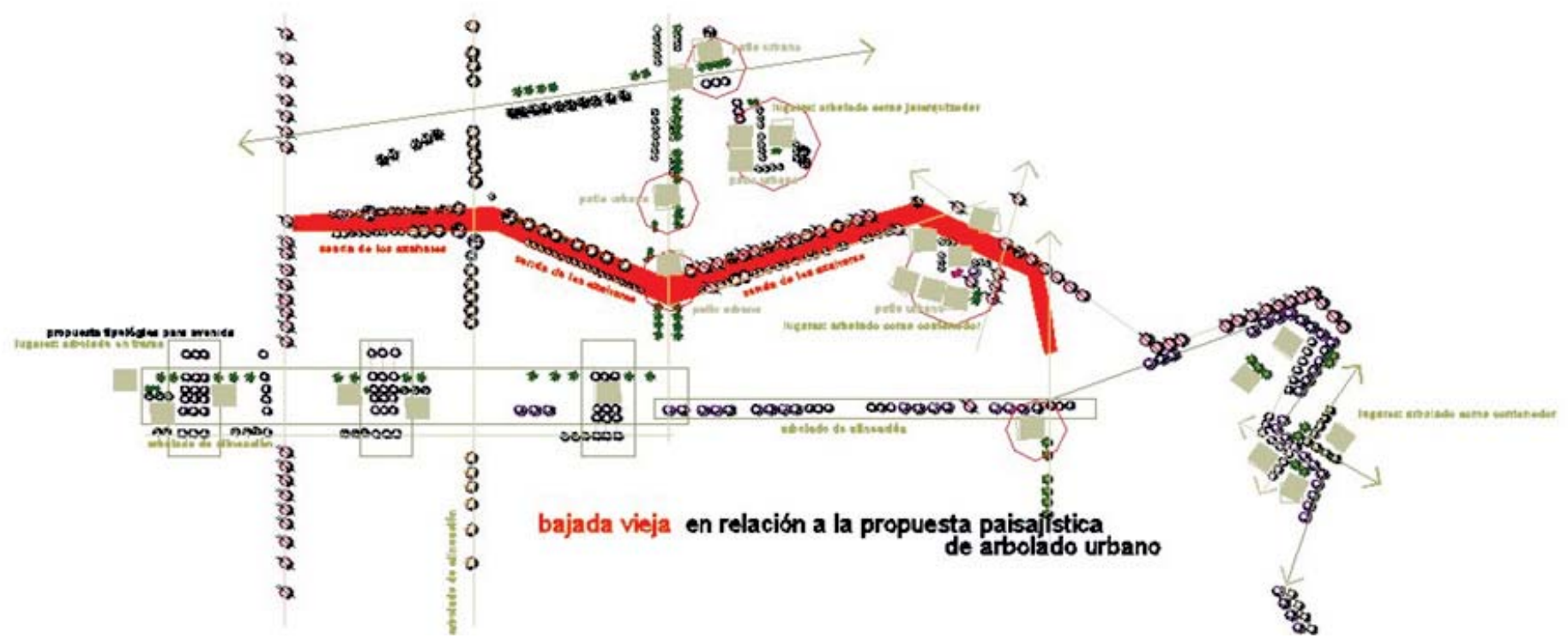

[Figura 9. Propuesta paisajística para el sector de intervención. Fuente: elaboración propia]

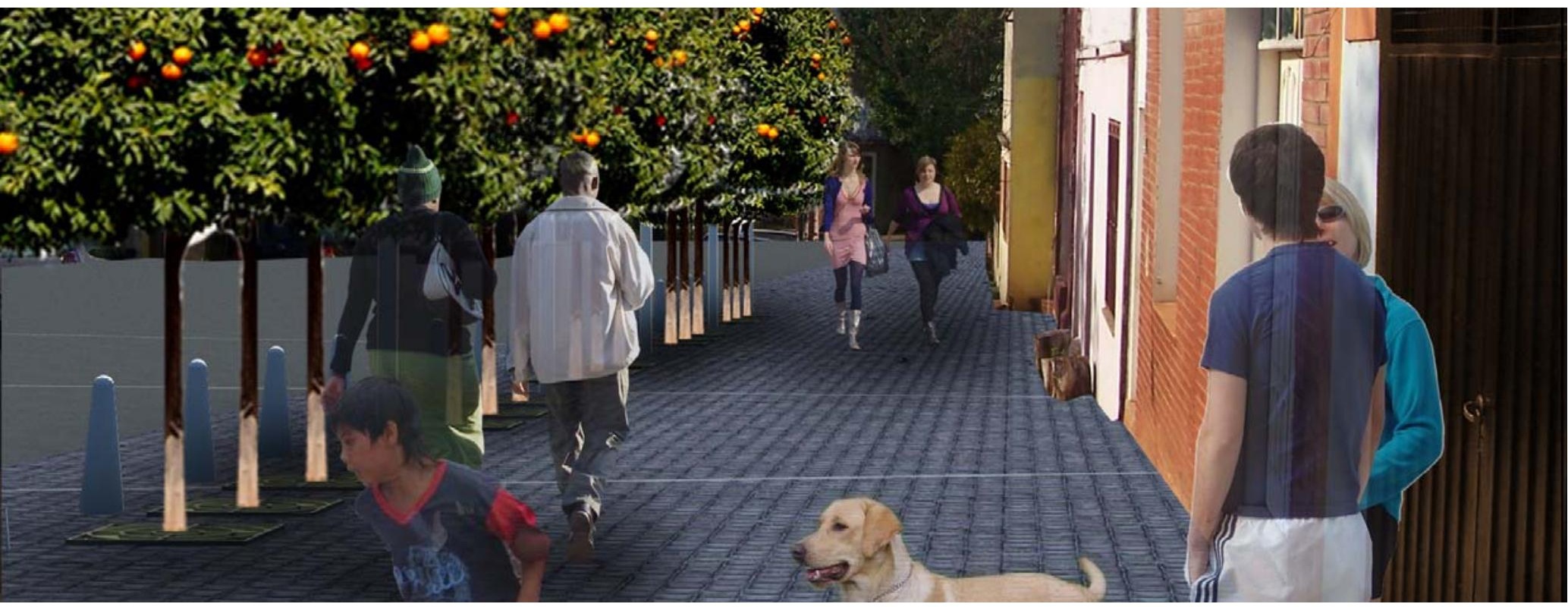

[Figura 10. Imagen vivencial de la senda de azahares. La vereda que se funde en la calle peato-vehicular. Fuente eleaboración propia]

los intersticios que dejan vacíos otras especies en las cuadras anterior y posterior. Los azahares despiden un aroma peculiar, que se expande por las calles exaltando los sentidos del peatón. Por otro lado, son sinónimo de tranquilidad, ya que sus efectos calmantes ayudan a eliminar molestias causadas por nervios y dolores de cabeza, potenciando así la cultura del "movimiento slow".(Figura 9)

A lo largo de la bajada vieja, se propone mantener dos criterios de espacio verde superficial: a la izquierda, de manera continua, lineal, sin interrupciones - a excepción de los ingresos a lotes privados-, rememorando las características existentes en la costanera; a la derecha, donde se ubica cada árbol, realizar la solución del encuentro con un cubrealcorque de un metro por un metro que otorgue de esta manera un carácter urbano peatonal, de continuidad de la superficie del solado para uso intensivo del peatón.

\section{Propuesta de modalidades y herramientas de gestión}

Gestionar la renovación y ordenamiento urbano requiere importantes inversiones iniciales para revertir la obsolescencia: adecuación de edificios abandonados, nuevos equipamientos en las áreas, mejoramiento y ampliación del equipamiento, consolidaciones viales, entre otras.
Implementar un urbanismo de renovación puede suscitar conflictos inmediatos con los vecinos, pudiendo surgir problemas de índole jurídica, económica y social. Por ello es necesario, como primera medida, consensuar con la sociedad en su conjunto y con los vecinos del sector en particular, de forma participativa, líneas de acción en lo inmediato y mediato. En este marco, se proponen los siguientes mecanismos de gestión.

\section{Del espacio urbano y el espacio público}

- Incorporar como extensión del Plan Estratégico la Gestión Urbana Participativa del sector, con el objetivo de lograr el acuerdo de la comunidad respecto de decisiones sobre la ciudad. - Pacto de ciudad. Realizar la firma del Pacto Ciudadano, un compromiso público entre actores, el cual s emprenderá después de un proceso participativo, como el plan estratégico que se está llevando adelante.

- Implementación de políticas y regulaciones urbanas que impacten en la valorización de los espacios y la estructura urbana, y en equipamientos que favorezcan la movilidad residencial y urbana.

- Usos del suelo. Facilitar la superposición de usos, de manera que el sector tenga vida durante la mayor parte del día, incluso en días feriados o festivos, pero sin alterar el perfil cul- 


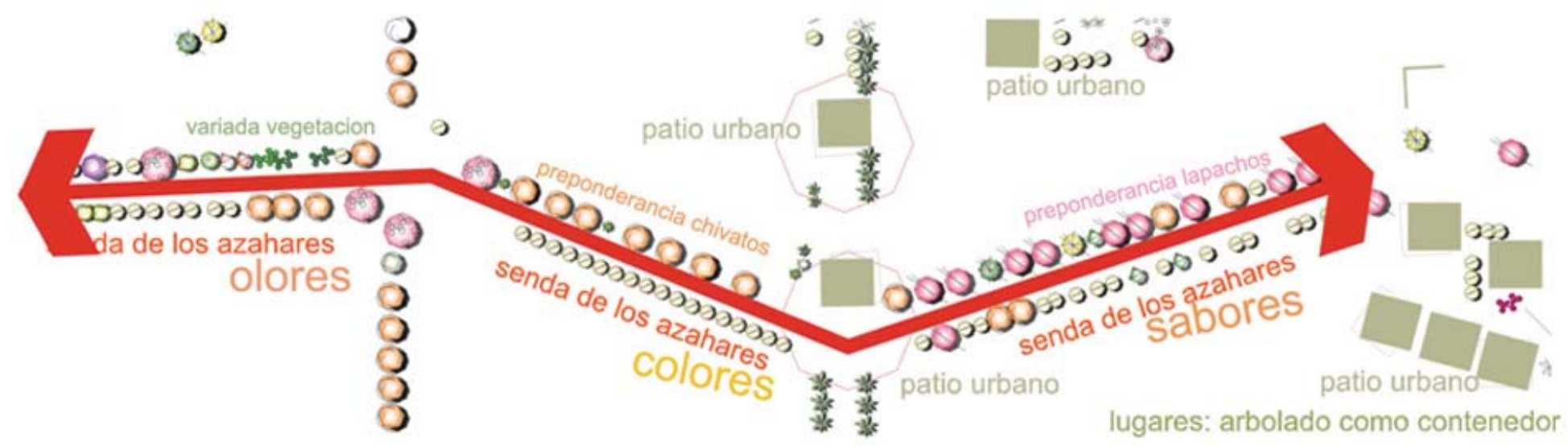

[Figura 11. Detalle de la "senda de los azahares" y sus características específicas por cuadra. Fuente: elaboración propia]

tural-turístico-recreativo que se intenta imprimir y potenciar.

- Vacíos urbanos. Acordar con los propietarios de baldíos, a través de convenios urbanísticos (público-privado) facilidades fiscales a aquellos que no construirán en el corto plazo, para dejar librado los vacíos al uso público y que se transformen en espacios recreativos.

- Cooperación mixta. Establecer convenios de cooperación mixta (público-privado) para el cuidado y mantenimiento de los espacios propuestos (sendas, bulevares, patios urbanos, miradores, etc.).

\section{De los edificios del sector}

- Pactos ciudadanos. Establecer acuerdos con los vecinos del sector para incorporar acciones de renovación en los edificios patrimoniales en uso y las viviendas con características propias del lugar que se encuentran en desuso.

- Políticas de incentivos. Condonar las deudas municipales o de servicios contraídas, o disminuir un porcentaje en el pago, a cambio del mejoramiento de las fachadas según la propuesta.

- Políticas económicas. Impulsarla eficiencia en el empleo de instrumentosfinancieros, fiscalesydeplanificación, parapotenciar la radicación de actividades turísticas y comerciales apropiadas. - Políticas ambientales. Aislar usos incompatibles con la actividad. Potenciar la adhesión a las propuestas arquitectónicopaisajísticas

- Crear un ente de cooperación mixta (integrado por sector público, privado, ONG, universidad, sector empresarial, sectores religiosos, entre otros), para acompañar la planificación integral del desarrollo urbano-arquitectónico del sector.

- Definir normativas específicas de protección de la identidad de La Bajada (colores que utilizar, formas, alturas, retiros y voladizos, materiales preferenciales, cartelerías y marquesinas). Estrategias de sensibilización y difusión en la enseñanza formal, no formal e informal.

- Estrategias de recuperación arquitectónica. Recuperar elementos faltantes de las fachadas originales; reparar componentes degradados, como muros, zócalos, carpinterías y rejas; cateo de colores para el restablecimiento de las paletas originales; reubicación de instalaciones y equipos auxiliares (como equipos de aire acondicionado) que desvirtúan la fachada original; trabajos especiales de iluminación de fachada. - Elaboración de un manual de buenas prácticas de intervención como instrumento orientador de futuras intervenciones de las fachadas de La Bajada.

- Asesoramiento gratuito a propietarios y profesionales para intervenciones en los edificios de La Bajada.

\section{REFLEXIONES FINALES}

La intervención de un área urbana que posee características que la diferencian de la trama preponderante de la ciudad puede ser la oportunidad de identificar un área para una recualificación espacial.

La propuesta tiene como nudo central la generación de un espacio integrado a la trama urbana, pero que se diferencia de esta, propiciando una cadencia nueva, una cultura slow, en la que el tiempo se detiene para propiciar el disfrute de actividades culturales, turísticas y de recreación.

Para ello se preservan los edificios de carácter patrimonial, se proponen intervenciones "quirúrgicas" sobre un espacio urbano consolidado y se plantean propuestas paisajísticas que colaboren con el disfrute del espacio público urbano.

Los concursos tienen por finalidad la búsqueda de propuestas innovadoras y apropiadas a un contexto determinado, pero de forma simultánea favorecen la democratización y la posibilidad de surgimiento de nuevos referentes. Por su parte, los premios reconocen los trabajos ya evaluados o realizados, permitiendo una nueva instancia de valoración desde una nueva perspectiva. 


\section{BIBLIOGRAFÍA}

ÁBALOS y HERERROS (1997) Áreas de impunidad. ACTAR.

BORJA, Jordi (2000) en Jornadas sobre Gestión de Territorio. Unidad de Gestión y Coordinación del Área Metropolitana -UGYCAMBA. Facultad de Arquitectura, Diseño y Urbanismo. UBA.

BRANDAO ALVES, Fernando M. (2003) Avaliaçao da qualidade do espaço público urbano. Proposta Metodológica. Textos Universitarios de Ciencias Sociales y Humanas.

ULLEN, Gordon (1978) El Paisaje Urbano. Ed. Blume.

DOBERTI, Roberto (2008). Espacialidades. Ed. Infinitos Buenos Aires.

DOMÉNECH, Martí (2003). La planificación y ostión de los espacios libres en la provincia de Barcelona. Evolución y progreso a lo largo de tres décadas. En El territorio como sistema: conceptos y herramientas de ordenación. Institut d'Edicions de la Diputació de Barcelona.

FALCON, Antoni (2007) Espacios verdes para una ciudad sostenible. Ed. GG. Barcelona.

FOLCH, Ramón (Coord.) (2003) El territorio como sistema. Conceptos y herramientas de ordenación. Diputación de Barcelona.

GUTIÉRREZ, Ramón (1983) El patrimonio Arquitectónico de los argentinos. Sociedad Central de Arquitectos. Instituto Argentino de Investigaciones en Historia de la Arquitectura y Urbanismo. HONORE, Carl (2008) Elogio de la lentitud. Ed. RBA Libros.

NOMBRE DEL PROYECTO: Bajada Vieja, Posadas, Misiones./ AUTORAS: Mgter. Arq. María José Roibón, Mgter. Arq. Claudia Pilar./ COLABORADORES: D. G. Cecilia Roca Zorat, Álvaro Lataza, Fernando Alberto./ INSTITUCIONES INVOLUCRADAS: Municipalidad de la Ciudad de Posadas y el Colegio de Arquitectos de Misiones. Universidad Nacional de Buenos Aires. Red de Diseño (DISUR)./ AÑO DE PROYECTO: 2011/ UBICACIÓN: ciudad de Posadas, provincia de Misiones./ TIPO DE ZONA: urbana./ EXTENSIÓN DE LA SUPERFICIE: 400 metros lineales de intervención y el entorno próximo.

CARACTERÍSTICAS FÍSICAS DEL ÁREA DE IMPLANTACIÓN: el área de la Bajada Vieja representa el sector más antiguo de la ciudad de Posadas (capital de la provincia de Misiones), con una fuerte relación con la funcionalidad del puerto, la topografía del sitio (con una pendiente apreciable) y su relación con la antigua Trinchera San José.

Su forma no responde a una propuesta de diseño planificada, sino que se ha ido construyendo con el paso del tiempo, por la sumatoria de intervenciones individuales, en general conectadas a la función comercial y mercantil del área. Por ello el sector "rompe" con la regularidad de la trama urbana, accidente que se enfatiza y revaloriza en el diseño, para distinguir, diferenciar y generar un polo en la ciudad de carácter cultural y turístico

IGNASI DE SOLÀ - MORALES. (2002) TERRITORIOS.

Editorial Gustavo Gilli, SA. Barcelona.

LYNCH, Kevin (1975) La imagen de la ciudad. Ed. GG. Barcelona.

MENGUAL MUÑOZ, Alberto. (Disponible a noviembre de 2005). Plaza y Jardín en el Paisaje Urbano. http://www.via-arquitectura.net.

Plan Estratégico Posadas 2022. Bases Concurso Internacional de Ideas Costa Central Uno de Posadas (2011).

RUANO, Miguel (1999). Eco Urbanism. Eco Urbanismo. Entornos humanos sostenibles: 60 proyectos. Editorial Gustavo Gili. Barcelona, España.

YEANG, Ken. Proyectar con la naturaleza. (1999). Bases ecológicas para el proyecto arquitectónico, Editorial Gustavo Gili, SA, Barcelona. 